\title{
Experimental Study on Dynamic Performance of Self-Compacting Lightweight Aggregate Concrete under Compression
}

\author{
Furong Li $\mathbb{D}^{1}{ }^{1}$ Zhenpeng Yu $\mathbb{D},{ }^{2}$ and Yanli $\mathrm{Hu}^{1}$ \\ ${ }^{1}$ Associate Professor, College of Civil Engineering, Yancheng Institute of Technology, Yancheng 224051, China \\ ${ }^{2}$ Ph.D. Student, School of Transportation, Southeast University, Nanjing 211102, China \\ Correspondence should be addressed to Zhenpeng Yu; 15751871206@163.com
}

Received 28 February 2019; Accepted 21 April 2019; Published 15 May 2019

Academic Editor: Emanuele Brunesi

Copyright (c) 2019 Furong Li et al. This is an open access article distributed under the Creative Commons Attribution License, which permits unrestricted use, distribution, and reproduction in any medium, provided the original work is properly cited.

In order to study the dynamic characteristics of the self-compacting lightweight aggregate concrete (SCLC) under uniaxial compression, 10 different strain rates $\left(10^{-5}-10^{-1} / \mathrm{s}\right)$ were set up to examine the uniaxial compressive dynamic performance of ordinary concrete, lightweight aggregate concrete, and SCLC, respectively. The failure modes and stress-strain curves of the samples under different loading conditions were obtained through experiment. The dynamic characteristics of the SCLC were analyzed by comparing the failure modes and testing data under different loading conditions. The following conclusions are drawn: the failure modes of the SCLC belong to destruction of shale ceramsite, which are similar to that of the lightweight aggregate concrete. The peak stress and elastic modulus of the self-compacting lightweight aggregate gradually increase with the increase of the loading strain rate, but the extent of increase of the peak stress is lower than that of the ordinary concrete and lightweight aggregate concrete. Affected by the loading strain rate and the random coupling of concrete, the peak strain of the selfcompacting lightweight aggregate shows a relatively discrete changing trend. At the same time, the compressive dynamic performance of the SCLC was analyzed from the perspective of failure mechanism with a quantitative point of view.

\section{Introduction}

Self-compacting concrete (SCC) is a rather new kind of concrete compared to other concrete materials. In addition to the advantages of ordinary concrete, SCC also has three unique characteristics as follows: first, it can be compacted directly relying on its own weight during the stirring process, without extra vibrating and compacting procedures; second, due to inherent characteristics, SCC can avoid the generation of original defects in the early stage; and third, SCC is able to resist external environmental erosion after hardening [1]. The SCLC refers to the SCC in which lightweight aggregate is used to replace coarse aggregate. It not only has the advantages of SCC but also is featured with low density, high strength, and strong antiseismic performance. Thus, it overcomes the defect of ordinary concrete that the coarse aggregate is inclined to sink and the defect of lightweight aggregate concrete that the lightweight aggregate is inclined to float up, under large fluidity. In view of this, the SCLC has broad application prospects in the future $[2,3]$.
As a multiphase material, the mechanical properties of concrete mainly involve three characteristics, i.e., nonlinearity, randomness, and dynamic rate dependence; as a consequence, concrete exhibits complicated mechanical performance in engineering applications, not only subject to static load but also dynamic load. For example, an engineering structure can be affected by the effects of seismic load, wind load, impact load, and blasting load, which are all closely related to the dynamic rate dependence effect of concrete $[4,5]$. Among earlier studies, Menzies and Sparks [6] and Bischoff and Perry [7] have examined the dynamic rate dependence of ordinary concrete and found that the stress-strain curve is significantly influenced by the dynamic rate dependence. Li et al. [8,9] carried out massive experimental studies on the dynamic rate dependence of ordinary concrete. Based on the elastoplastic damage theory, they elaborated the dynamic rate dependence effect of ordinary concrete and analyzed its failure modes. Shi et al. [10] examined the dynamic rate dependence of large aggregate and wet sieve concrete. With respect to lightweight aggregate concrete, 
10 different strain rates were set up in the literature [11] to comparatively analyze the dynamic characteristics of ordinary concrete and lightweight aggregate concrete; the results indicate that the influence of dynamic rate on lightweight aggregate concrete is more significant than that on ordinary concrete. However, the existing studies on SCLC are mainly to analyze the basic mechanical properties, durability, and working performance, while no research has been carried out on compression dynamics. Therefore, studies on the compression dynamic performance of SCLC have an important engineering significance [1-3].

This paper carries out an experimental study on the dynamic performance of ordinary concrete, lightweight aggregate concrete, and SCLC under compression. Ten different strain rates $\left(10^{-5} \sim 10^{-1} / \mathrm{s}\right)$ were set up to obtain the stress-strain curves and failure modes for different concretes by using the hydraulic servo testing machine. The dynamic characteristics of the three kinds of concrete were then compared and quantitatively analyzed by extracting the peak stress, elastic modulus, and peak strain (the strain corresponding to the peak stress) from the stress-strain curves. On such basis, the relationships between the strain rate and peak stress and between the strain rate and elastic modulus were established for different concretes.

\section{Experimental Overview}

2.1. Sample Preparation. This study examined three kinds of concrete: ordinary concrete, lightweight aggregate concrete, and SCLC. The ordinary concrete is prepared using ordinary Portland cement P.O 42.5 and urban tap water, with the designed strength of $30 \mathrm{MPa}(\mathrm{C} 30)$; the fine aggregate used is made of natural river sands; the coarse aggregate used is made of gravels at the particle size of $4 \sim 16 \mathrm{~mm}$; and there are no other additives. The lightweight aggregate concrete has a designed strength of $30 \mathrm{MPa}$ (LC30); its difference from ordinary concrete lies in that shale ceramsite is used to replace the coarse aggregate (i.e., gravels). The SCLC has a designed strength of $30 \mathrm{MPa}$ (SCLC30); its main difference from ordinary concrete and lightweight aggregate concrete lies in the use of mineral powder (fly ash) and water-reducing agent. The "Ordinary Portland Cement" GB175-2007 stipulates that the hydraulic cementitious material made of Portland cement clinker, 5\%-20\% of mixed materials, and an appropriate portion of gypsum through grinding is called ordinary Portland cement. The strength rating of cement is a sign reflecting the strength of cement, and the compressive strength is generally used as a measurement indicator. Its testing standard is mainly the strength of cement mortar after hardening for 28 days. If the compressive strength of an ordinary Portland cement at $28 \mathrm{~d}$ is $42.5 \mathrm{MPa}$, then the strength rating of this cement is 42.5 . The cement used in the present study is ordinary Portland cement P.O 42.5. The ingredient ratios of the three kinds of concrete are shown in Table 1. The physical properties of shale ceramsite are shown in Table 2.

The pouring method of ordinary concrete (light aggregate concrete) is significantly different from that of the SCLC. In the pouring process of ordinary concrete (light aggregate concrete), the coarse aggregate, fine aggregate, and cement are poured into the mixer all at once according to the ratio, as shown in Table 1. After stirring evenly, the mixture is slowly added and mixed with water. The well-mixed concrete materials are then poured into a mold of $100 \mathrm{~mm} \times 100 \mathrm{~mm} \times 100 \mathrm{~mm}$, which is transferred onto a vibrating table for compacting. The stirring method for lightweight aggregate concrete is the same as ordinary concrete. For the preparation of SCLC, the cement, fine aggregate, and mineral powders are poured into the mixer first. After stirring evenly, the mixture is slowly added and mixed well with water containing water-reducing agent. Finally, coarse aggregate is poured into the mixture for thorough stirring $[1,2]$. All the test samples are cured for 24 hours first, taken out from the mold, and then placed in a standard curing room at the temperature of $20^{\circ} \mathrm{C} \pm 3^{\circ} \mathrm{C}$ and humidity of $95 \%$ for 28 days to achieve the designed strength.

2.2. Test Equipment. The hydraulic servo is used in the present study to examine the influence of strain rate on concrete. The whole set of equipment consists of a hydraulic actuator, a load displacement acquisition system, and a central control unit. The equipment is built in with a highprecision load sensor and a high-precision displacement sensor, and the measurement data can be automatically recorded by the attached program. The precision of this equipment satisfies the desired experimental requirements, as shown in Figure 1.

2.3. Test Loading. Based on the objectives of this study, the concrete cube is designed into a dimension of $100 \mathrm{~mm} \times 100 \mathrm{~mm} \times 100 \mathrm{~mm}$, with the strength of $30 \mathrm{MPa}$. In view of the friction effect of concrete during the loading process, three layers of polyethylene plastic film with additional two layers of mechanical butter for each are applied to eliminate the friction on the loading surface. This antifriction method has been widely recognized by scholars both at home and abroad.

The concrete materials correspond to different strain rates under different loading conditions, i.e., creep $\left(10^{-8} \sim 10^{-6} / \mathrm{s}\right)$, static loading $\left(10^{-6} \sim 10^{-5} / \mathrm{s}\right)$, seismic action $\left(10^{-3} \sim 10^{-2} / \mathrm{s}\right)$, impact $\left(1 \sim 10^{2} / \mathrm{s}\right)$, and explosion $\left(10^{2} \sim 10^{3} /\right.$ s). A total of 10 different loading strain rates are set up, which are $1.0 \times 10^{-5} / \mathrm{s}, \quad 5.0 \times 10^{-5} / \mathrm{s}, \quad 1.0 \times 10^{-4} / \mathrm{s}, \quad 5.0 \times 10^{-4} / \mathrm{s}$, $1.0 \times 10^{-3} / \mathrm{s}, 2.0 \times 10^{-3} / \mathrm{s}, 5.0 \times 10^{-3} / \mathrm{s}, 1.0 \times 10^{-2} / \mathrm{s}, 2.0 \times 10^{-2} / \mathrm{s}$, and $5.0 \times 10^{-2} / \mathrm{s}$, respectively [4]. Specifically, $1.0 \times 10^{-5} / \mathrm{s}$ refers to the static loading strain rate, while the dynamic loading strain rate is ranged from $1.0 \times 10^{-4} / \mathrm{s}$ to $1.0 \times 10^{-1} / \mathrm{s}$, considering the loading rate of seismic action. Three concrete samples are tested for each strain rate, and the mean value is taken for analysis. The stress-strain curve of each concrete sample is obtained from the hydraulic servo.

In order to perform the dynamic performance test, the loading method mainly adopts hybrid control of force and displacement. Firstly, force control is conducted mainly to achieve a preloading purpose from $0 \mathrm{MPa}$ to $0.05 f_{\mathrm{c}}$ and then unloading to $0 \mathrm{MPa}$. This process is repeated for three times. Then, the displacement control loading mode is conducted 
TABLE 1: The ingredient radio of concrete.

\begin{tabular}{lcccccc}
\hline & \multicolumn{5}{c}{ The mass of each ingredient in 1 cubic meter of concrete $(\mathrm{kg})$} \\
Concrete strength & Cement & Water & Coarse aggregate/shale ceramsite & Fine aggregate & Mineral powder & Water-reducing agent \\
\hline C30 & 461 & 175 & 1252 & 512 & - & - \\
LC30 & 460 & 200 & 670 & 650 & - & - \\
SCLC30 & 388 & 197 & 300 & 710 & 166 & 8.32 \\
\hline
\end{tabular}

TABLe 2: Physical properties of lightweight aggregate.

\begin{tabular}{lccccccc}
\hline & $\begin{array}{c}\text { Cylinder } \\
\text { strength } \\
(\mathrm{MPa})\end{array}$ & $\begin{array}{c}\text { Bulk } \\
\text { density } \\
\left(\mathrm{kg} / \mathrm{m}^{3}\right)\end{array}$ & $\begin{array}{c}\text { Apparent } \\
\text { density } \\
\left(\mathrm{kg} / \mathrm{m}^{3}\right)\end{array}$ & $\begin{array}{c}\text { Hygroscopic } \\
\text { coefficient } \\
(1 \mathrm{~h})(\%)\end{array}$ & $\begin{array}{c}\text { Hygroscopic } \\
\text { coefficient } \\
(24 \mathrm{~h})(\%)\end{array}$ & $\begin{array}{c}\text { Porosity } \\
(\%)\end{array}$ & $\begin{array}{c}\text { Maximum } \\
\text { particle } \\
\text { size } D_{\text {max }}(\mathrm{mm})\end{array}$ \\
\hline $\begin{array}{l}\text { Lightweight } \\
\text { aggregate concrete }\end{array}$ & 6.9 & $\begin{array}{c}789 \\
\left(1400^{*}\right)\end{array}$ & 1398 & 2.18 & 3.28 & 48.2 & 16 \\
\hline
\end{tabular}

* Bulk density value of gravels.

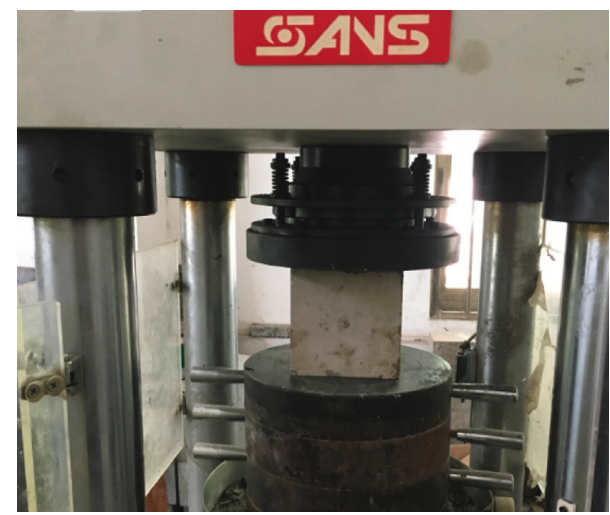

FIgURE 1: The experimental equipment.

according to the strain rates mentioned above, i.e., imposing loading by displacement control until the test sample is broken.

\section{Test Results and Analysis}

3.1. Failure Mode. In the experimental research of concrete materials and concrete structural applications, failure mode analysis based on test results plays an important role. For the purpose of the present study, which is to examine the dynamic performance of SCC, the failure mode analysis also has an important meaning. The failure modes of concrete were obtained from the experiment, as shown in Figure 2.

As shown in Figure 2, the concrete loading surface forms uniform cracks under the uniaxial static load $\left(1.0 \times 10^{-5} / \mathrm{s}\right)$, and the failure is mainly the shear failure of lightweight aggregate. This is significantly different from the failure mode of ordinary concrete under static load, which is mainly the failure of bonding materials, while the aggregate does not break. With the increase of the loading strain rate, the number of main cracks on the loading surface of lightweight aggregate concrete is reduced to $2 \sim 3$, and the cracks would continue developing until the test sample is totally broken through. Meanwhile, the cracks under dynamic load are mainly oblique cracks, which is consistent with the failure mode of ordinary concrete in the dynamic characteristics
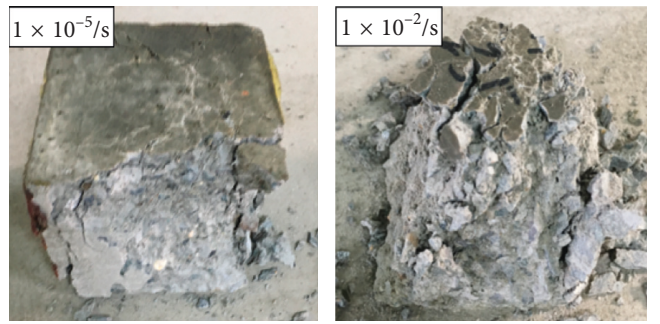

(a)
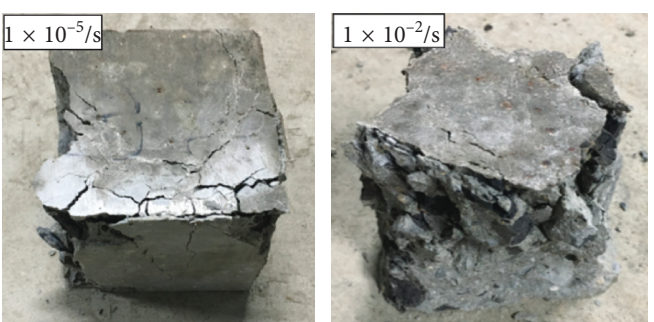

(b)
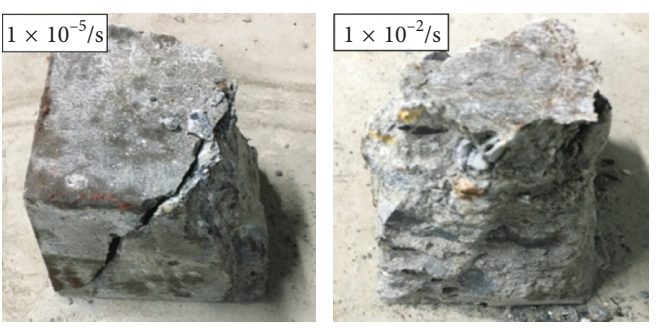

(c)

FIgURE 2: Failure modes of concrete samples under uniaxial compression at different strain rates: (a) C30, (b) LC30, and (c) SCLC30.

test. This is because, with the increase of the loading strain rate, the cracks of lightweight aggregate concrete cannot fully develop like the cracks of ordinary concrete under static load; on the contrary, the sample action time is getting shorter and shorter due to the dynamic effect, unable to form a uniform stress state in a short time. As a consequence, the cracks would not develop uniformly and form the failure mode, as shown above. Different from the failure mode of ordinary concrete, the failure of lightweight aggregate 
concrete is mainly the shear failure due to the dynamic effect, rather than the failure of bonding materials. The dynamic performance failure modes of ordinary concrete and lightweight aggregate concrete under uniaxial compression are consistent with the failure mode descriptions of these two kinds of concrete in the literature [11].

The compressive dynamic performance failure mode of the SCLC is different from that of the ordinary concrete and lightweight aggregate concrete. When the loading strain rate is relatively low (i.e., $1.0 \times 10^{-5} / \mathrm{s}, 5.0 \times 10^{-5} / \mathrm{s}$, and $1.0 \times 10^{-4} / \mathrm{s}$ ), the failure mode of SCLC is $45^{\circ}$ oblique shear failure; when the loading strain rate is greater than $1.0 \times 10^{-4} / \mathrm{s}$, the failure mode of SCLC becomes tapered column failure. Meanwhile, similar to the lightweight aggregate concrete, the failure of SCLC is always attributed to the shear failure of lightweight aggregate. This is because the compacting strength of lightweight aggregate is significantly lower than that of the new gravels.

3.2. Stress-Strain Curve. The stress-strain curves are obtained from the uniaxial compressive tests on the three different kinds of concrete. Then, the dynamic characteristics are compared and analyzed by extracting the peak stress, peak strain, and elastic modulus from the stress-strain curves. The dynamic characteristic stress-strain curves of the three kinds of concrete are shown in Figure 3.

The stress-strain curve of concrete differs significantly at different strain rates. Specifically, the peak stress is obviously different; with the increase of the loading strain rate, the peak stresses of all the three concretes are gradually increased, while the changes in the peak strain and elastic modulus are relatively insignificant with the change of the strain rate and need to be further elaborated. At different strain rates, the stress-strain curves of ordinary concrete, lightweight aggregate concrete, and SCLC conform to the basic characteristics of uniaxial compression and exhibit good continuity and smoothness. Meanwhile, with the increase of the strain rate, the energy consumption ability of concrete increases significantly. This is consistent with Zeng Shajie's conclusions on the dynamic characteristics of ordinary concrete: the dynamic characteristics curve of ordinary concrete is featured with continuity and smoothness and consistent with the basic description of the uniaxial compressive experiment; with the increase of the strain rate, the energy consumption ability of ordinary concrete increases significantly. To highlight the differences among the three kinds of concrete, the declining part of the stress-strain curve of SCLC shows obvious brittle failure characteristics compared with that of the ordinary concrete and lightweight aggregate concrete, and its plastic deformation ability is relatively poor. This is possibly because the SCLC has a lower content of coarse aggregate, and the compactness of its test sample is higher than that of the ordinary concrete and lightweight aggregate concrete.

3.3. Peak Stress. In the dynamic characteristics study of ordinary concrete, peak stress is an important parameter in the stress-strain curve, and the dynamic improvement coefficient is generally used to explore the influence of dynamic rate dependence on the peak stress of ordinary concrete, i.e., [9]:

$$
\alpha_{\mathrm{DIF}-\sigma}=\frac{\sigma_{\mathrm{d}}}{\sigma_{\mathrm{s}}}
$$

where $\sigma_{\mathrm{s}}$ denotes the peak stress of the stress-strain curve at the static loading of $1.0 \times 10^{-5} / \mathrm{s}, \sigma_{\mathrm{d}}$ denotes the peak stress of the stress-strain curve under dynamic loading conditions, and the corresponding strain rates in this study are $5.0 \times 10^{-5} / \mathrm{s}, 1.0 \times 10^{-4} / \mathrm{s}, 5.0 \times 10^{-4} / \mathrm{s}, 1.0 \times 10^{-3} / \mathrm{s}$, $2.0 \times 10^{-3} / \mathrm{s}, \quad 5.0 \times 10^{-3} / \mathrm{s}, \quad 1.0 \times 10^{-2} / \mathrm{s}, \quad 2.0 \times 10^{-2} / \mathrm{s}$, and $5.0 \times 10^{-2} / \mathrm{s}$, respectively.

The dynamic improvement coefficient can also be used in the present study to examine the dynamic characteristics of the three different kinds of concrete. The peak stresses of the stress-strain curves obtained from the tests at different strain rates are shown in Table 3.

As shown in Table 3, the peak stress of normal concrete changes significantly under dynamic loading compared to static loading $\left(1.0 \times 10^{-5} / \mathrm{s}\right)$ and increases gradually with the increase of the loading strain rate. When the strain rate is equal to $5.0 \times 10^{-2} / \mathrm{s}$, the peak stress is increased by $33 \%$, while the peak stress of lightweight aggregate concrete and SCLC is increased by $36 \%$ and $24 \%$, respectively. According to the test results of Menzies and Sparks [6] and Bischoff and Perry [7] regarding the influence of strain rate on ordinary concrete under uniaxial compression, the peak stress of ordinary concrete is increased by around $40 \%$ when the strain rate reaches $5.0 \times 10^{-2} / \mathrm{s}$. Shi et al. [10] reported that, when the loading strain rate increased from $2.0 \times 10^{-5} / \mathrm{s}$ to $2.0 \times 10^{-2} / \mathrm{s}$, the peak stress of ordinary concrete was increased by $34.26 \%$. Li et al. [8] examined the dynamic characteristics of ordinary concrete with different strengths and found that, when the loading strain rate increased from $1.0 \times 10^{-5} / \mathrm{s}$ to $1 \times 10^{-1} / \mathrm{s}$, the peak stress was increased by $30 \% \sim 40 \%$. The literature [11] studied the dynamic characteristics of ordinary concrete and lightweight aggregate concrete; when the loading strain rate increased from $1.0 \times 10^{-5} / \mathrm{s}$ to $5.0 \times 10^{-2} / \mathrm{s}$, the peak stress of the two kinds of concrete was increased by $34.36 \%$ and $54.48 \%$, respectively, suggesting that the dynamic characteristics imposed a stronger influence on ordinary concrete than on the lightweight aggregate concrete. In the comparison of the relationship between the peak stress and loading strain rate for the three kinds of concrete, the influence of loading strain rate on the peak stress of SCLC, ordinary concrete, and lightweight aggregate concrete is getting stronger. The peak stress improvement coefficient of ordinary concrete and lightweight aggregate concrete under the influence of strain rate is around $30 \% \sim 40 \%$, while the influence of dynamic rate on the peak stress of SCLC is significantly weaker than that on ordinary concrete and lightweight aggregate concrete. The conclusions of this study regarding the influence of dynamic characteristics on ordinary concrete and lightweight aggregate concrete are different to the literature [11].

As shown by the analysis results, the peak stress of all the three concretes increases with the increase of the strain rate, which is consistent with the concrete failure mechanics. 


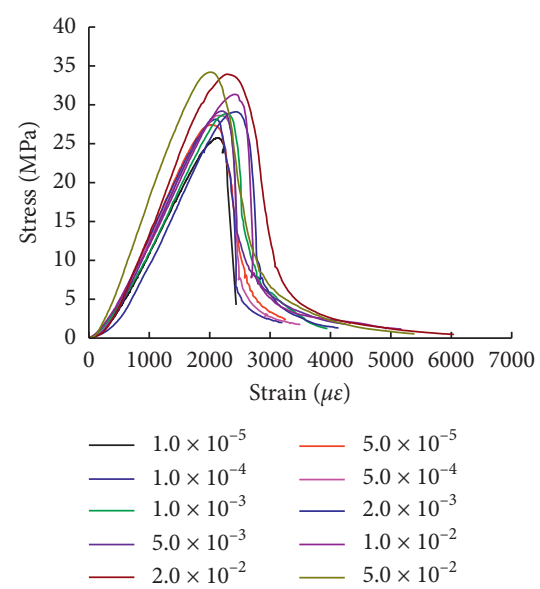

(a)
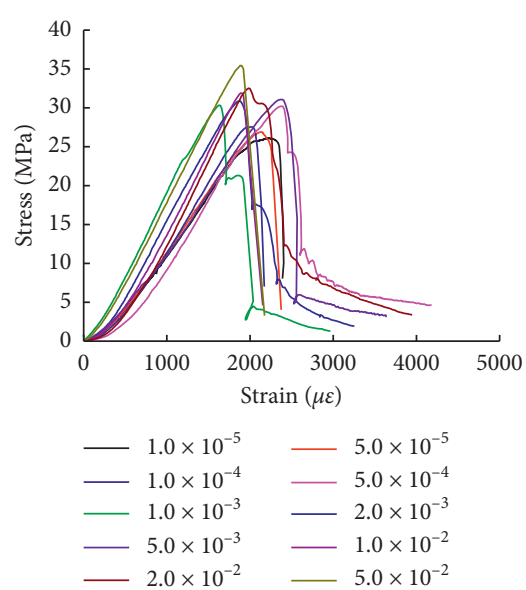

(b)
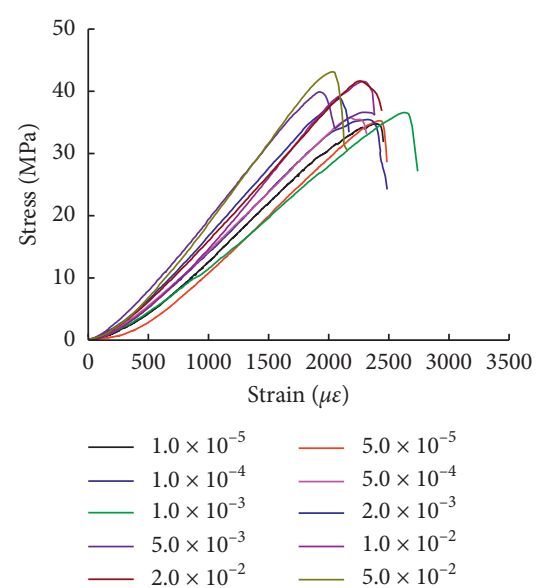

(c)

FIgURE 3: The uniaxial compressive stress-strain curves of concretes at different strain rates: (a) C30, (b) LC30, and (c) SCLC30.

TABLE 3: The peak stress at different strain rates (unit: MPa).

\begin{tabular}{lcccccc}
\hline & \multicolumn{2}{c}{ C30 } & \multicolumn{2}{c}{ LC30 } & \multicolumn{2}{c}{ SCLC30 } \\
Strain rate & $\begin{array}{c}\text { Peak } \\
\text { stress }\end{array}$ & $\begin{array}{c}\text { Dynamic } \\
\text { improvement coefficient }\end{array}$ & $\begin{array}{c}\text { Peak } \\
\text { stress }\end{array}$ & $\begin{array}{c}\text { Dynamic } \\
\text { improvement coefficient }\end{array}$ & $\begin{array}{c}\text { Peak } \\
\text { stress }\end{array}$ & $\begin{array}{c}\text { Dynamic } \\
\text { improvement coefficient }\end{array}$ \\
\hline $1.0 \times 10^{-5}$ & 25.72 & 1.00 & 26.09 & 1.00 & 34.77 & 1.00 \\
$5.0 \times 10^{-5}$ & 26.54 & 1.03 & 26.89 & 1.03 & 35.26 & 1.01 \\
$1.0 \times 10^{-4}$ & 27.33 & 1.06 & 27.54 & 1.06 & 35.46 & 1.02 \\
$5.0 \times 10^{-4}$ & 29.28 & 1.14 & 30.21 & 1.16 & 36.79 & 1.03 \\
$1.0 \times 10^{-3}$ & 30.44 & 1.18 & 30.34 & 1.16 & 38.88 & 1.05 \\
$2.0 \times 10^{-3}$ & 31.36 & 1.22 & 30.89 & 1.19 & 39.90 & 1.15 \\
$5.0 \times 10^{-3}$ & 31.63 & 1.23 & 31.07 & 1.22 & 41.59 & 1.19 \\
$1.0 \times 10^{-2}$ & 32.67 & 1.27 & 31.89 & 1.25 & 43.14 & 1.20 \\
$2.0 \times 10^{-2}$ & 33.94 & 1.32 & 32.52 & 1.36 & & 1.24 \\
$5.0 \times 10^{-2}$ & 34.20 & 1.33 & 35.43 & & &
\end{tabular}

Under the effect of a high strain rate, the concrete failure exhibits the phenomenon of hysteresis, resulting in the fact that the peak strain of dynamic strain rate is significantly higher than that under the static state and increases with the increase of the strain rate. This is clearly reflected in Figure 2, i.e., the failure mode of concrete.

In order to further analyze and examine the influence of loading strain rate on the peak stress of concrete from the quantitative point of view, the dynamic strain rate and static loading strain rate are processed by dimensionless treatment, followed by logarithm calculation, and the dynamic peak stress and static loading peak stress are also processed by dimensionless treatment. Then, mathematical regression analysis is carried out according to the following equation:

$$
\alpha_{\mathrm{DIF}}=1+a \lg \left(\frac{\dot{\dot{\varepsilon}_{\mathrm{s}}}}{\dot{\dot{\varepsilon}_{\mathrm{d}}}}\right) .
$$

Based on the test data of peak stress points of the three concretes at different strain rates, the mathematical regression analysis, following equation (2), can derive the relationship between the peak stress and loading strain rate for different concretes, as shown in Figure 4.
As shown in Figure 4, the peak stress of all the three concretes increases significantly with the increase of the strain rate and is linearly correlated with the logarithm of the strain rate after dimensionless treatment. The relationships between the peak stresses of the various concretes and the strain rates obtained by mathematical regression are shown in equations (3)-(5):

C30:

$$
\alpha_{\mathrm{DIF}-\sigma}=1+0.0898 \lg \left(\frac{\dot{\varepsilon_{\mathrm{s}}}}{\dot{\dot{\varepsilon}_{\mathrm{d}}}}\right)
$$

LC30:

$$
\alpha_{\mathrm{DIF}-\sigma}=1+0.08102 \lg \left(\frac{\dot{\varepsilon_{\mathrm{s}}}}{\dot{\dot{\varepsilon}_{\mathrm{d}}}}\right) .
$$

SCLC30:

$$
\alpha_{\mathrm{DIF}-\sigma}=1+0.05475 \lg \left(\frac{\dot{\varepsilon_{\mathrm{s}}}}{\dot{\dot{\varepsilon}_{\mathrm{d}}}}\right) .
$$

According to equations (3) (5), the peak stress increases with the increase of the loading strain rate at different strain rates for all the three concretes and is linearly correlated with 


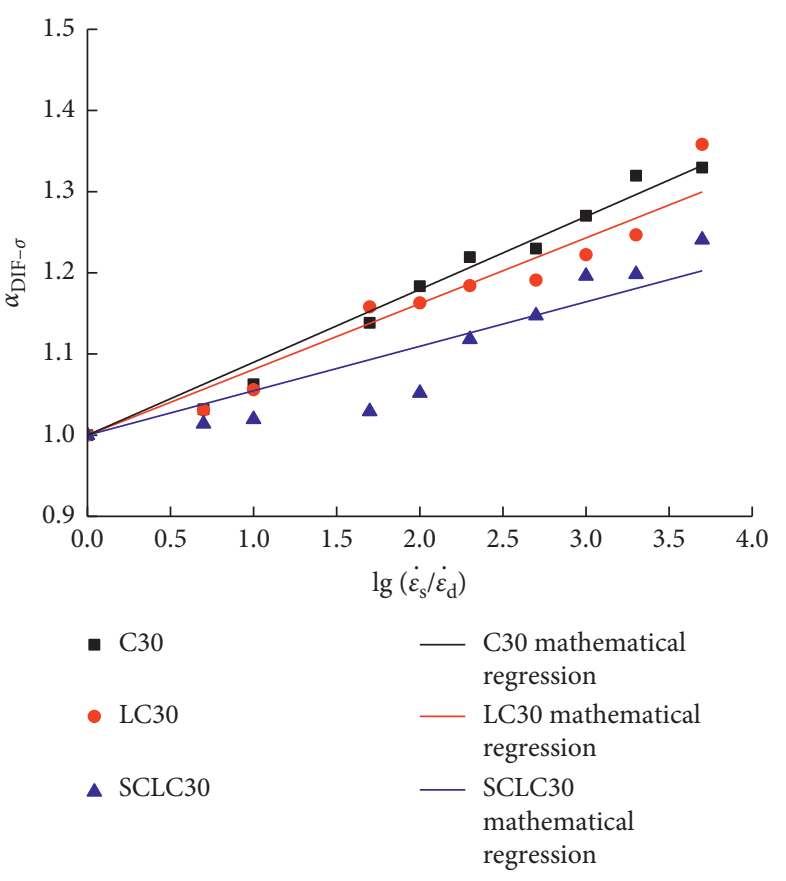

Figure 4: The peak stress improvement coefficient at different strain rates.

the logarithm of the strain rate after dimensionless treatment. For the relationship between the peak stress of the three concretes and the strain rate expressed by the slope of the mathematical regression equation, the slope of SCLC is significantly smaller than that of the ordinary concrete and lightweight aggregate concrete. The slopes confirm that the influence of loading strain rate on the peak stress of ordinary concrete is the strongest, followed by lightweight aggregate concrete and SCLC.

3.4. Peak Strain. Different from the influence of strain rate on the peak stress, the influence of strain rate on the peak strain does not show any clear regularity. There are three viewpoints currently, which are (1) the peak strain of concrete increases with the increase of strain rate; (2) the peak strain of concrete almost shows no change with the change of strain rate; and (3) the peak strain of concrete decreases with the increase of strain rate. According to the related literature [9], when the strain rate is in the range of $1.0 \times 10^{-5} / \mathrm{s} \sim 1.0 \times 10^{-1} / \mathrm{s}$, the peak strain of concrete varies in the range of $-30 \% \sim 40 \%$.

In order to further analyze the influence of loading strain rate on the peak strain of concrete from the quantitative point of view, the dynamic strain rate and static loading strain rate are processed by dimensionless treatment first, followed by logarithm calculation, and then, the dynamic peak strain and static loading peak strain are also processed by dimensionless treatment, as shown in Figure 5.

According to Figure 5, when the loading rate is ranged from $1.0 \times 10^{-5}$ to $5.0 \times 10^{-2}$, the peak strain change rate of ordinary concrete, lightweight aggregate concrete, and SCLC

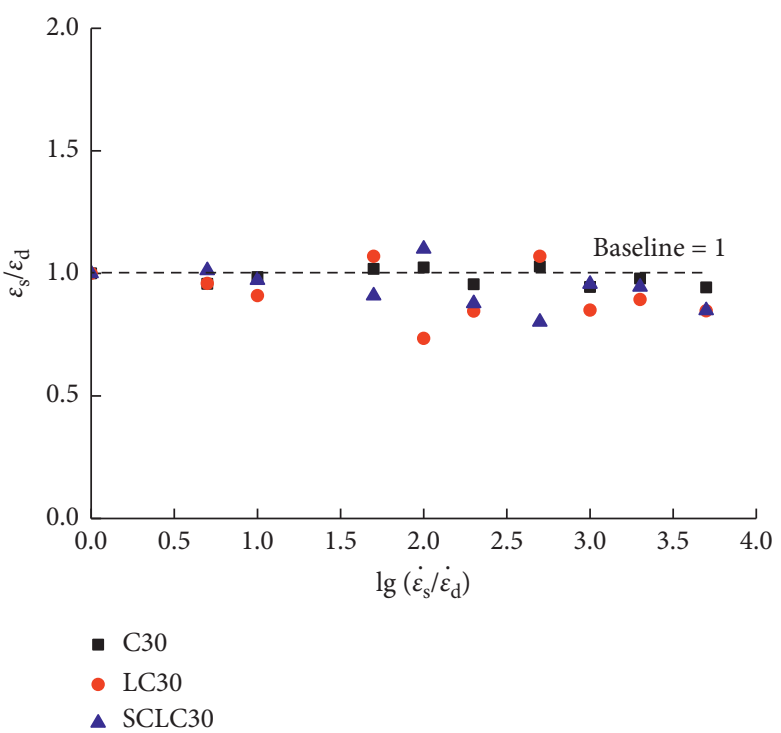

FIGURE 5: The peak strain improvement coefficient at different strain rates.

is ranged $-5.73 \% \sim 2.82 \%,-26.54 \% \sim 6.99 \%$, and $-19.78 \% \sim$ $10.04 \%$, respectively. The peak strain of all the three concretes shows obvious randomness, and the coupling effect of randomness and rate dependence leads to irregular changes of the peak strain.

3.5. Elastic Modulus. Elastic modulus is one of the important parameters in the stress-strain curve, which plays an important role in the study of mechanical properties of concrete. The parameter of elastic modulus is extracted in the present study to examine the influence of loading strain rate on the concrete dynamic performance [12].

In order to facilitate accurate quantitative study of the elastic modulus of concrete materials, the $50 \%$ peak stress is used as the elastic modulus:

$$
E=\frac{\sigma_{0.5}}{\varepsilon_{0.5}},
$$

where $\sigma_{0.5}$ denotes the $50 \%$ peak stress and $\varepsilon_{0.5}$ denotes the strain value corresponding to the $50 \%$ peak stress, as shown in Table 4.

According to Table 4, in relation to the static elastic modulus (i.e., the elastic modulus of concrete at the strain rate of $1.0 \times 10^{-5} / \mathrm{s}$ ), the elastic modulus of ordinary concrete is increased gradually with the increase of strain rate. When the loading strain rate is equal to $5.0 \times 10^{-2}$, the elastic modulus of ordinary concrete, lightweight aggregate concrete, and SCLC is increased by $41 \%, 64 \%$, and $48 \%$, respectively. It can be seen that the influence of loading strain rate on the elastic modulus of SCLC is less significant than that on the ordinary concrete and lightweight aggregate concrete.

In order to further analyze the influence of loading strain rate on the elastic modulus of concrete from the quantitative analysis, the dynamic strain rate and static loading strain rate are processed by dimensionless treatment, followed by 
TABLe 4: The elastic modulus at different strain rates (unit: $\times 10^{3} \mathrm{MPa}$ ).

\begin{tabular}{|c|c|c|c|c|c|c|}
\hline \multirow[b]{2}{*}{ Strain rate } & \multicolumn{2}{|r|}{$\mathrm{C} 30$} & \multicolumn{2}{|r|}{ LC30 } & \multicolumn{2}{|r|}{ SCLC30 } \\
\hline & $\begin{array}{l}\text { Peak } \\
\text { stress }\end{array}$ & $\begin{array}{c}\text { Dynamic } \\
\text { improvement coefficient }\end{array}$ & $\begin{array}{l}\text { Peak } \\
\text { stress }\end{array}$ & $\begin{array}{c}\text { Dynamic } \\
\text { improvement coefficient }\end{array}$ & $\begin{array}{l}\text { Peak } \\
\text { stress }\end{array}$ & $\begin{array}{c}\text { Dynamic } \\
\text { improvement coefficient }\end{array}$ \\
\hline $1.0 \times 10^{-5}$ & 13.54 & 1.00 & 11.24 & 1.00 & 13.21 & 1.00 \\
\hline $5.0 \times 10^{-5}$ & 14.60 & 1.08 & 11.62 & 1.03 & 13.29 & 1.01 \\
\hline $1.0 \times 10^{-4}$ & 14.61 & 1.08 & 12.07 & 1.07 & 14.40 & 1.09 \\
\hline $5.0 \times 10^{-4}$ & 15.13 & 1.12 & 12.12 & 1.08 & 15.24 & 1.15 \\
\hline $1.0 \times 10^{-3}$ & 15.65 & 1.16 & 12.38 & 1.10 & 15.33 & 1.16 \\
\hline $2.0 \times 10^{-3}$ & 17.28 & 1.28 & 13.59 & 1.21 & 16.12 & 1.22 \\
\hline $5.0 \times 10^{-3}$ & 16.19 & 1.20 & 14.54 & 1.29 & 16.77 & 1.27 \\
\hline $1.0 \times 10^{-2}$ & 18.21 & 1.34 & 15.46 & 1.38 & 17.35 & 1.31 \\
\hline $2.0 \times 10^{-2}$ & 18.25 & 1.35 & 17.70 & 1.58 & 19.07 & 1.44 \\
\hline $5.0 \times 10^{-2}$ & 19.10 & 1.41 & 18.42 & 1.64 & 19.55 & 1.48 \\
\hline
\end{tabular}

logarithmic calculation. Meanwhile, the dynamic elastic modulus and static loading elastic modulus are also processed by dimensionless treatment and then performing mathematical regression analysis according to equation (3):

$$
\alpha_{\mathrm{DIF}-E}=\frac{E_{\mathrm{s}}}{E_{\mathrm{d}}}=1+b \lg \left(\frac{\dot{\varepsilon_{\mathrm{s}}}}{\dot{\varepsilon_{\mathrm{d}}}}\right) .
$$

Based on the test data of elastic modulus of the three kinds of concrete at different strain rates, the mathematical regression analysis, following equation (7), derives the relationship between the elastic modulus and the strain rate for different concretes, as shown in Figure 6.

According to Figure 6, the elastic modulus of all concretes increases with the increase of the loading strain rate and is linearly correlated with the logarithm of strain rate after dimensionless treatment. The relationship equation between the elastic modulus and loading strain rate for different concretes can be obtained using the mathematical regression method, as shown in equations (8)-(10):

C30:

$$
\alpha_{\mathrm{DIF}-E}=1+0.10151 \lg \left(\frac{\dot{\varepsilon_{\mathrm{s}}}}{\dot{\varepsilon_{\mathrm{d}}}}\right)
$$

LC30:

$$
\alpha_{\mathrm{DIF}-E}=1+0.13023 \lg \left(\frac{\dot{\varepsilon_{\mathrm{s}}}}{\dot{\varepsilon_{\mathrm{d}}}}\right) .
$$

SCLC30:

$$
\alpha_{\mathrm{DIF}-E}=1+0.11178 \lg \left(\frac{\dot{\varepsilon_{\mathrm{s}}}}{\dot{\varepsilon_{\mathrm{d}}}}\right) .
$$

According to equations (8) (10), the elastic modulus of all the three concretes increases significantly with the increase of the strain rate and is linearly correlated with the logarithm of the strain rate after dimensionless treatment. The changing rate of elastic modulus with the strain rate can be expressed by the slope of the mathematical regression equation, and it can be seen that the slope of ordinary concrete is significantly smaller than that of the SCLC and lightweight aggregate concrete. This is because that the elastic modulus parameter of concrete is the coupling analysis value of the stress parameter

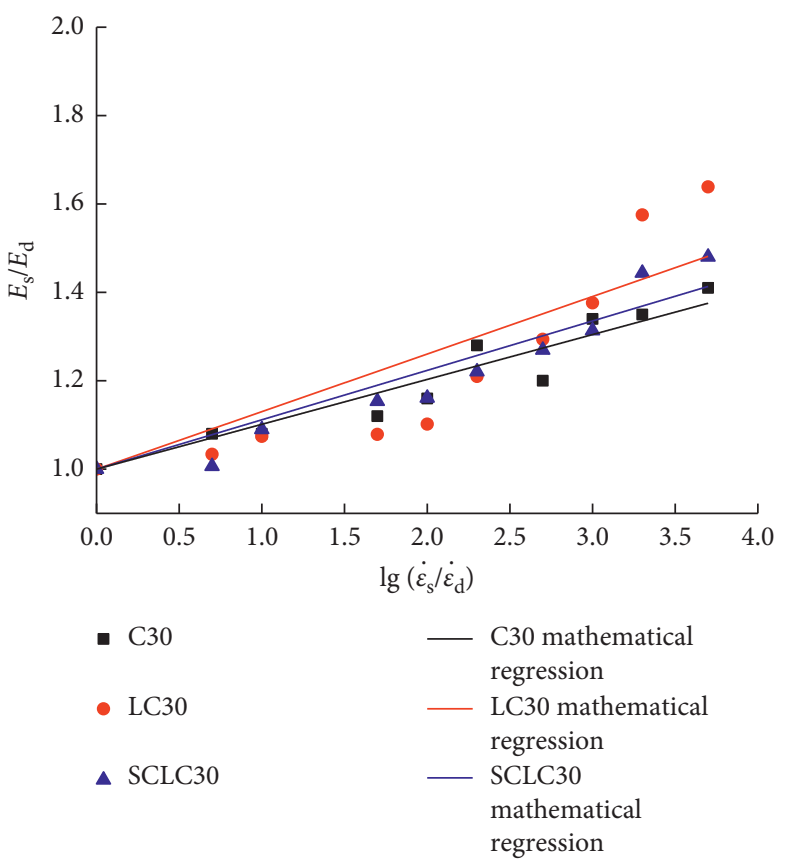

FIGURE 6: The elastic modulus improvement coefficient of concrete at different strain rates.

and strain parameter, where the influence of loading strain rate on the strain parameter is rather discrete, and the peak stress increases significantly with the increase of the loading strain rate. The coupling effect of the strain parameter and peak stress parameter leads to the fact that the influence of strain rate on the elastic modulus of ordinary concrete is the weakest, followed by light aggregate concrete, while the influence is the most significant on the SCLC. Meanwhile, the results also suggest that the loading strain rate has a stronger influence on the peak stress of concrete than on the peak strain of concrete.

\section{Conclusions}

The present study examined and compared the dynamic rate effects of ordinary concrete, lightweight aggregate concrete, and SCLC and reached the following conclusions: 
(1) Influenced by the strain rate, the failure mode of the three kinds of concrete shows obvious changes. The cracks of ordinary concrete and lightweight aggregate concrete develop from static state vertical cracks gradually into oblique cracks affected by dynamics, and the failure of SCLC develops from oblique shear failure gradually into tapered column failure. At the same time, the failure of ordinary concrete is mainly the failure of bonding materials, while the failure of lightweight aggregate concrete and SCLC is mainly the shear failure of lightweight aggregate.

(2) With the increase of the loading strain rate, the peak stress and elastic modulus of ordinary concrete, lightweight aggregate concrete, and SCLC are increased significantly. The increase of peak stress of the three concretes with the increase of loading strain rate is $33 \%, 36 \%$, and $24 \%$, respectively, when expressed in percentage. The SCLC is significantly less influenced by strain rate compared with the ordinary concrete and lightweight aggregate concrete. The influence of the loading strain rate on the peak strain is rather discrete for all the three concretes, which is mainly caused by the coupling effect of randomness and rate dependence.

(3) According to the test data of this study, the peak stress and elastic modulus after dimensionless treatment are linearly correlated with the logarithm of the strain rate after dimensionless treatment for all the three concretes. Affected by the randomness and rate dependence, no obvious relationship is observed between the peak strain and loading strain rate for all the three concretes.

\section{Data Availability}

The nature of the data is the experimental data of concrete subjected to uniaxial loading under different strain rates. The data used to support the findings of this study are available from the corresponding author upon request.

\section{Conflicts of Interest}

The authors declare that there are no conflicts of interest.

\section{Acknowledgments}

This work was supported by the National Key R\&D Program of China (2016YFC0401704). The authors gratefully acknowledge the financial support.

\section{References}

[1] W. C. Yun, J. K. Yong, H. C. Shin et al., "An experimental research on the fluidity and mechanical properties of highstrength lightweight self-compacting concrete," Cement \& Concrete Research, vol. 36, no. 9, pp. 1595-1602, 2006.

[2] X. Wu, Z.-M. Wu, J.-J. Zheng, T. Ueda, and S.-H. Yi, “An experimental study on the performance of self-compacting lightweight concrete exposed to elevated temperature,"
Magazine of Concrete Research, vol. 65, no. 13, pp. 780-786, 2013.

[3] Z. Yu, Q. Huang, F. Li et al., "Experimental study on mechanical properties and failure criteria of self-compacting concrete under biaxial tension-compression," Journal of Materials in Civil Engineering, vol. 31, no. 5, pp. 40190451401904510, 2019.

[4] S. Shang and Y. Song, "Dynamic biaxial tensile-compressive strength and failure criterion of plain concrete," Construction \& Building Materials, vol. 40, pp. 322-329, 2013.

[5] X. D. Chen, S. X. Wu, and J. K. Zhou, "Large-beam tests on mechanical behavior of dam concrete under dynamic loading," Journal of Materials in Civil Engineering, vol. 27, no. 10, article 06015001, 2015.

[6] J. B. Menzies and P. R. Sparks, "The effect of rate of loading upon the static and fatigue strengths of plain concrete in compression," Magazine of Concrete Research, vol. 25, no. 83, pp. 73-80, 1973.

[7] P. H. Bischoff and S. H. Perry, "Compressive behaviour of concrete at high strain rates," Materials and Structures, vol. 24, no. 6, pp. 425-450, 1991.

[8] J. Li, X. Yan, and X. Ren, "Large-sample experimental study on uniaxial compressive behavior of concrete under different loading," Journal of Building Structures, vol. 37, no. 8, pp. 66-75, 2016, in Chinese.

[9] S. Zeng and J. Li, "Experimental study on uniaxial compression behavior of concrete under dynamic loading," Journal of Tongji University (Natural Science), vol. 41, no. 1, pp. 7-10, 2016, in Chinese.

[10] L. Shi, Y. Song, and S. H. E. N. Lu, "Experimental study on uniaxial compression properties of large aggregate and wet-screened concrete at different strain rates," World Earthquake Engineering, vol. 32, no. 2, pp. 270-276, 2016, in Chinese.

[11] X. Sun and X. Xie, "Compression dynamic performance of ordinary concrete and lightweight Aggregate concrete," Journal of Building Materials, vol. 21, no. 3, pp. 376-381, 2018, in Chinese.

[12] F. Li, Y. Zhang, J. Liu, L. Zhang, and S. Fang, "The dynamical response characteristics of elastic-plastic coal under dynamic load," Journal of Natural Gas Science and Engineering, vol. 29, pp. 497-505, 2016. 


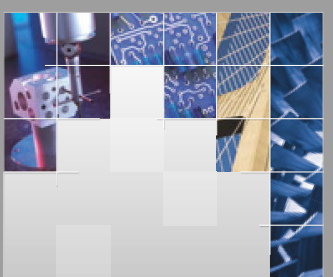

\section{Enfincering}
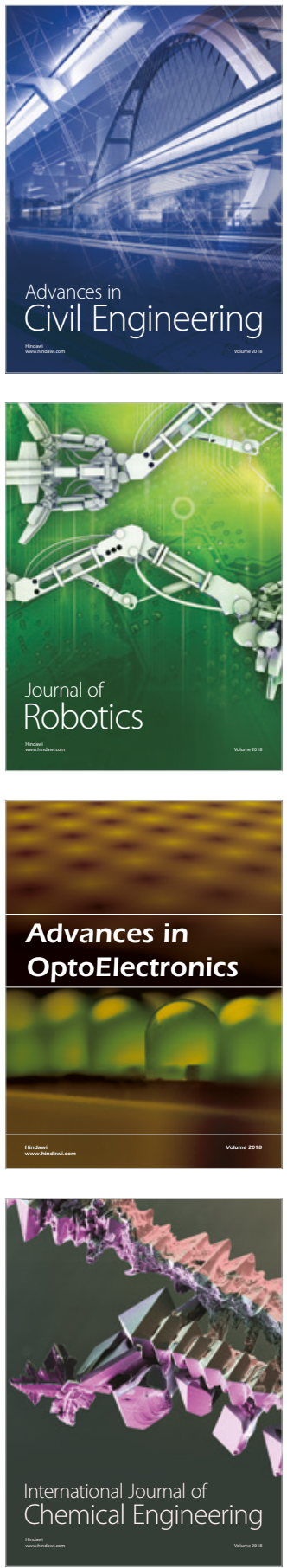

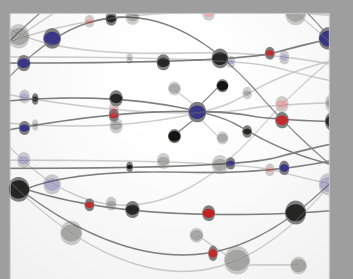

\section{Rotating \\ Machinery}

The Scientific World Journal

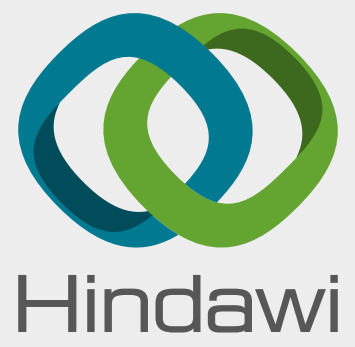

Submit your manuscripts at

www.hindawi.com
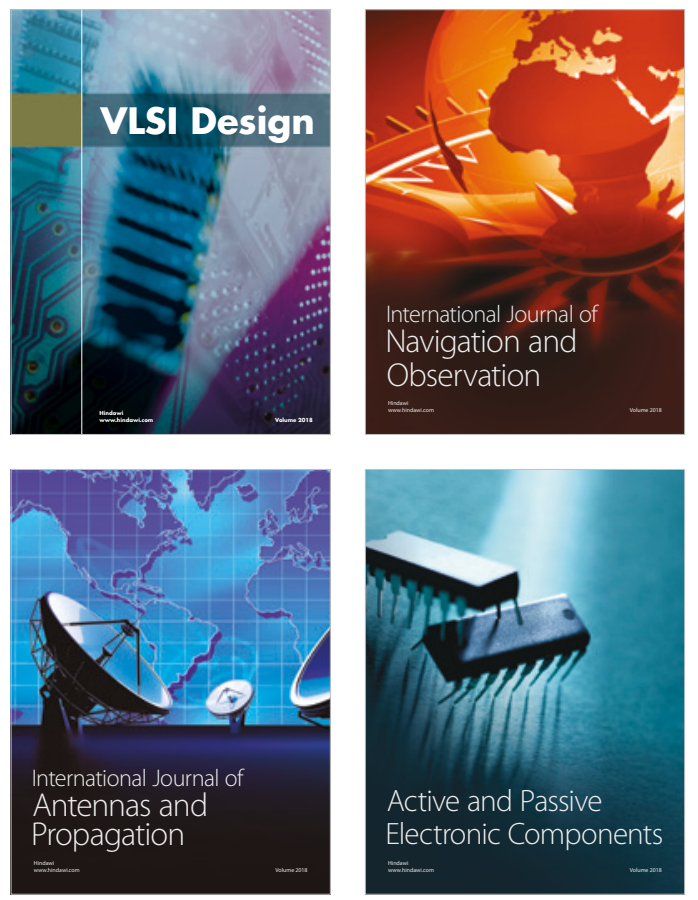
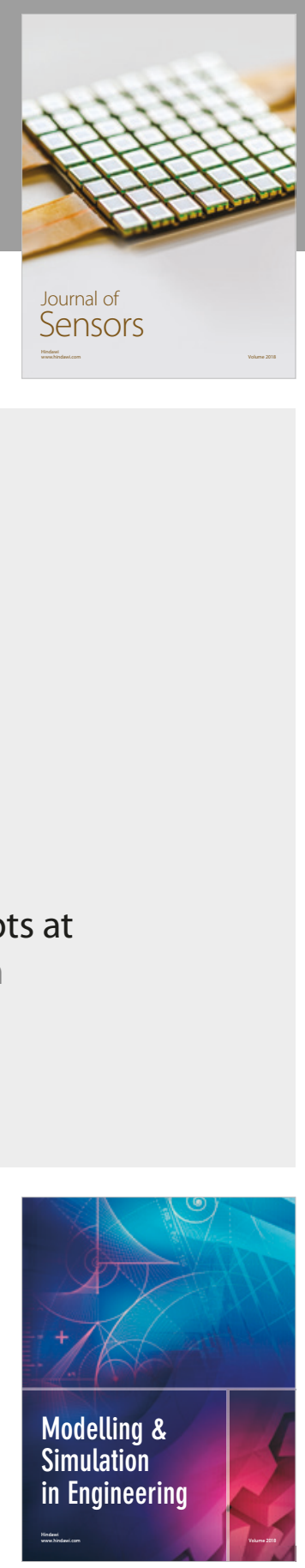

\section{Advances \\ Multimedia}
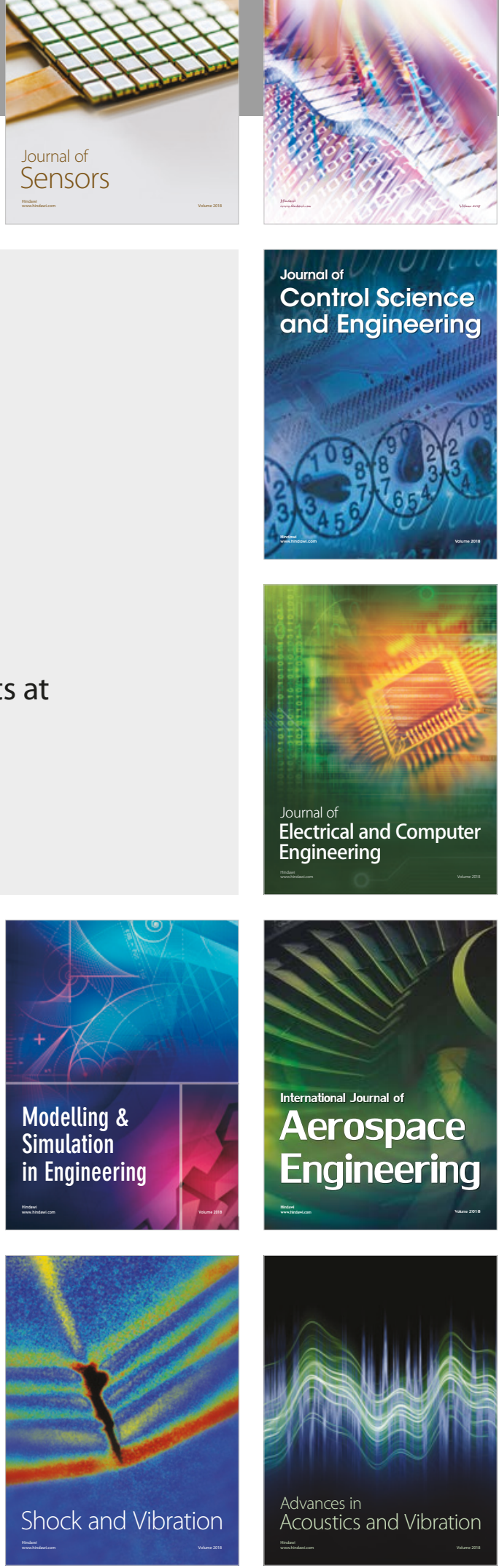